\title{
DISCUSSION
}

\section{Soil, basin and soil-building-soil interaction effects on motions of Mexico City during seven earthquakes}

\author{
EVANGELIA GARINI*, IOANNIS ANASTASOPOULOS $\dagger$, GEORGE GAZETAS $\ddagger$, NICK O’RIORDAN§, \\ PAWAN KUMAR\|, KIRK ELLISON\| and FRANCISCO CIRUELA-OCHOA $₫$
}

\begin{abstract}
Contribution by Nick O'Riordan, Pawan Kumar, Kirk Ellison and Francisco Ciruela-Ochoa

The forensic analysis of seismograph recordings from strong motion earthquakes is an essential component of the development of performance-based seismic design of buildings, and the authors (Garini et al., 2020) are to be congratulated on advancing and contextualising ground motions from a range of recent earthquakes that have affected, sometimes catastrophically, the built environment of Mexico City. The purpose of this discussion note is to
\end{abstract}

(a) provide further evidence to that advanced by the authors that seismograph records from the Puebla earthquake of 19 September 2017 and the earlier Chiapas earthquake of 8 September 2017 show that ground motions recorded in the urbanised area of the Mexico City basin are strongly influenced by the urban fabric itself, rather than a natural 'basin' effect

(b) show how the authors' analyses could be improved using vertical array data available historically for two of the urban sites considered by the authors, and some consequences for back-analysis of the record at the Secretaria de Communicaciones y Telegrafos (SCT) recording station.

\section{(a) Puebla earthquake of 19 September 2017}

The authors of this discussion note were, between 2015 and 2018, heavily involved in the design and construction of the new international airport for Mexico (NAIM) on the essentially undeveloped lake bed of the former Lake Texcoco, approximately $10 \mathrm{~km}$ north-east of the urban area of Mexico City. A triaxial accelerometer array, IINGEN2, was installed during the works. The location of this array is superimposed on Fig. 1 of Garini et al. (2020).

The dashed line on Fig. 27 represents the north-eastern extent of urban Mexico City that otherwise covers the 'lake zone' of Gaceta Oficial del Distrito Federal (2004). It can be seen from Fig. 27 that, together with the Aux station, all the seismograph records considered by Garini et al. (2020) were from urban sites, and add that this is also the case with the UNAM-GEER (National Autonomous University of Mexico-Geotechnical Extreme Events Reconnaissance) report (Mayoral et al., 2019). Aux station is identified as 'NZ31' by Mayoral et al. (2019) and, in common with all

\footnotetext{
* National Technical University of Athens, Greece (Orcid:0000-0001-6972-5980).

$\dagger$ ETH-Zürich, Zürich, Switzerland.

\$ National Technical University of Athens, Greece.

$\S$ Arup Group Ltd, London, UK.

II Arup Group Ltd, San Francisco, CA, USA.

I Arup Group Ltd, New York, NY, USA.
}

sites in the deepest, lowest strength part of the lake-bed zone (zone IIId), was not examined by those authors.

The results from IINGEN2 and Aux are reproduced in Figs 28 and 29, respectively. It can be seen that the duration of shaking with an amplitude greater than $15 \mathrm{~cm} / \mathrm{s}^{2}(0 \cdot 015 \mathrm{~g})$ at the urban Aux station extends well beyond the $90 \mathrm{~s}$ of primary shaking recorded at IINGEN-2.

Pseudo-spectral accelerations, up to a period of $5 \mathrm{~s}$ from these two recording stations, are compared in Fig. 30 together with the earlier, Chiapas event as recorded at Aux station (IINGEN-2 did not trigger under the Chiapas event).

There are short-period $(<0.7 \mathrm{~s})$ excitations evident at IIGEN-2 in Fig. 29 that are likely to be due to interaction with trial embankments and post-tensioned slabs located nearby; however, there is a strong peak at about $2.5 \mathrm{~s}$. This is close to the fundamental soil period for the site obtained using the Seed et al. (1988) approximation, applied to the shear wave profile obtained by shear and compression wave velocity measured using suspension logging techniques (PS logging), as given in Fig. 31.

The variation of shear wave velocity with ground elevation (metres above sea level) is shown in Fig. 31.

The Aux station records are further decomposed in Fig. 32 to show how the second phase beating after the $140 \mathrm{~s}$ time mark (Puebla) and $300 \mathrm{~s}$ time mark (Chiapas) dominates the spectrum for periods longer than $4 \mathrm{~s}$.

The ground conditions are not known with certainty at Aux station; however, they are likely to be even softer than those at IINGEN-2, due to the absence of the preloading effects of industrial brine pumping in the upper $60 \mathrm{~m}$ of the strata that took place between 1945 and 1995 at the latter site. The long-period beating that appears to have been induced by the urban fabric at Aux station is at a fundamental site period of 5 s. Fig. 31 also shows the importance of the 'coda', especially for the lower-intensity shaking of the Chiapas 2017 event.

Using the CU station as a representative bedrock record, Fig. 33 illustrates the spectral amplification at the Aux site for both the Puebla and the earlier Chiapas event. Spectral amplification at the IINGEN-2 site was similar to that recorded at Aux station for the Puebla 2017 event.

Speculative analytical work by Guegen et al. (2002), using observations in the Roma Norte district at the stiffer, western edge of the basin, suggested that urban interaction effects could be anticipated if the kinematic interaction ratio of the buildings to the underlying soil is higher than approximately $0 \cdot 1$. Using Guegen's methodology, with a first mode frequency for a two-storey, $5.9 \mathrm{~m}$ high city block calculated to be $3.7 \mathrm{~Hz}$, on $40 \mathrm{~m}$ of soft soil with a fundamental site frequency of $0.25 \mathrm{~Hz}$, the kinematic interaction ratio for the urban area of Aux station is 0.87 . Thus kinematic interaction at a city block level is almost certain to have contributed to the second phase beating measured at the Aux station during both 8 and 19 September 2017 earthquakes and, to the west of the urban Mexico City area, to the catastrophic damage of many buildings during the 19 September event. 


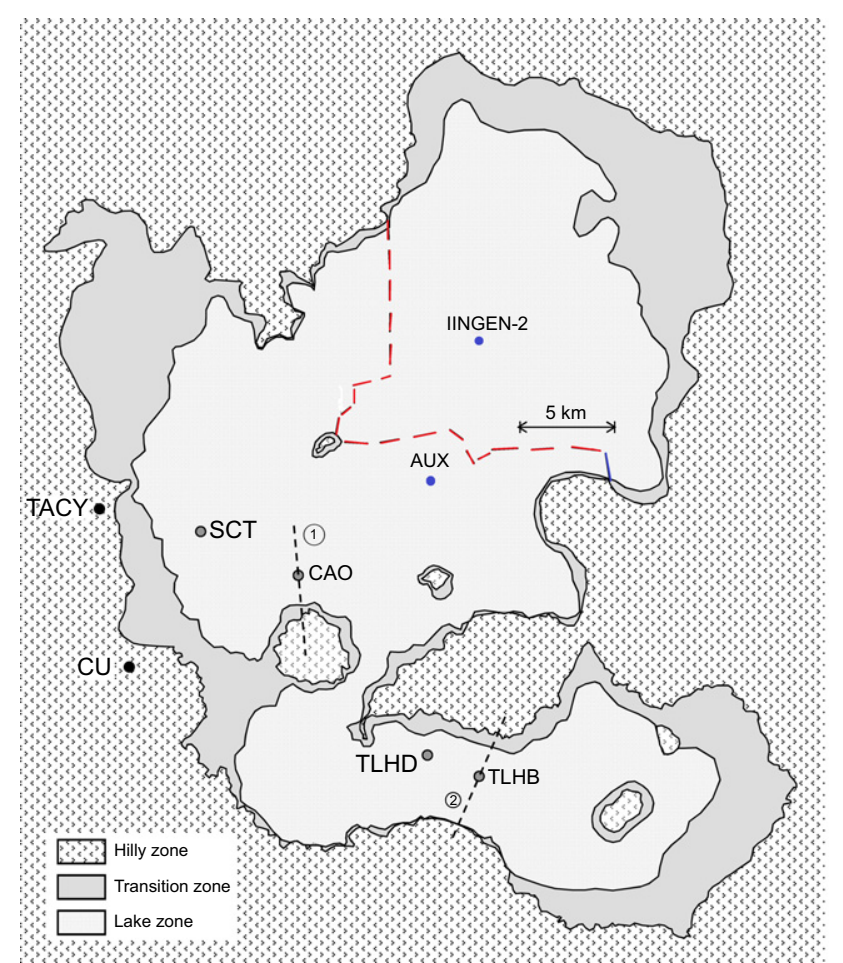

Fig. 27. Location of recording stations IINGEN-2 and Aux, superimposed on Fig. 1 from the paper by Garini et al. (2020)
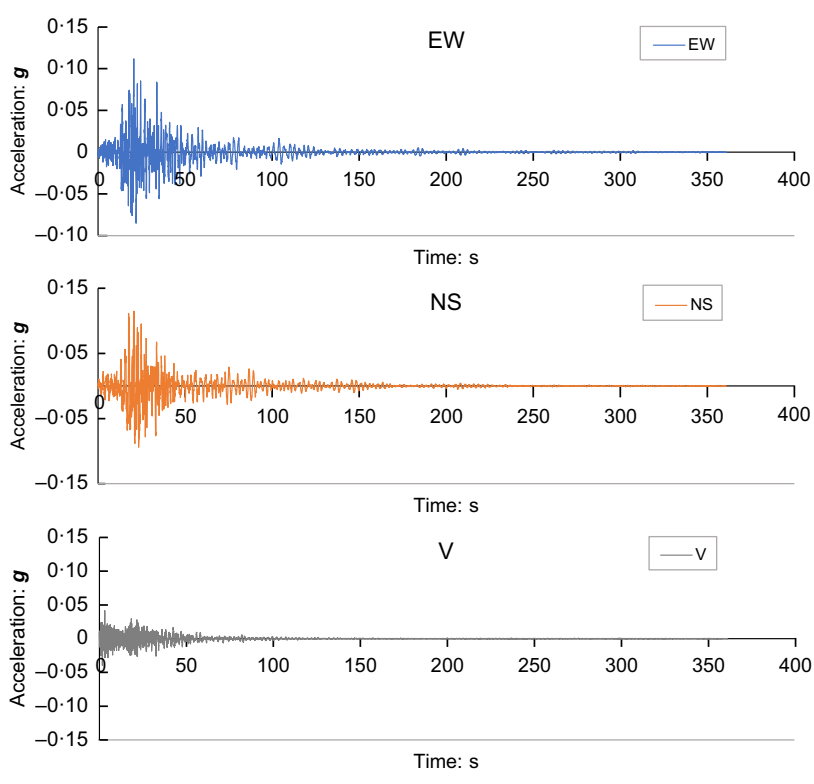

Fig. 28. Seismographs from IIGEN 2 station, NAIM site on former Lake Texcoco Puebla earthquake

\section{(b) Use of vertical array data for CAO and SCT site back-analysis}

Kumar et al. (2017) and O'Riordan et al. (2018a) describe the back-analysis of seismograph records from vertical arrays for CAO and SCT sites given in the Mexican strong motion database (Alcántara et al., 2000) for the earthquakes listed in Table 2. The vertical arrays were installed to depths of $60 \mathrm{~m}(\mathrm{CAO})$ and $25 \mathrm{~m}$ (SCT).

The authors carried out bi-directional site response analyses using the finite-element program LS-Dyna together with soil layers modelled using the Mat_Hysteretic soil model that adopted the parameters for Lake Texcoco clays

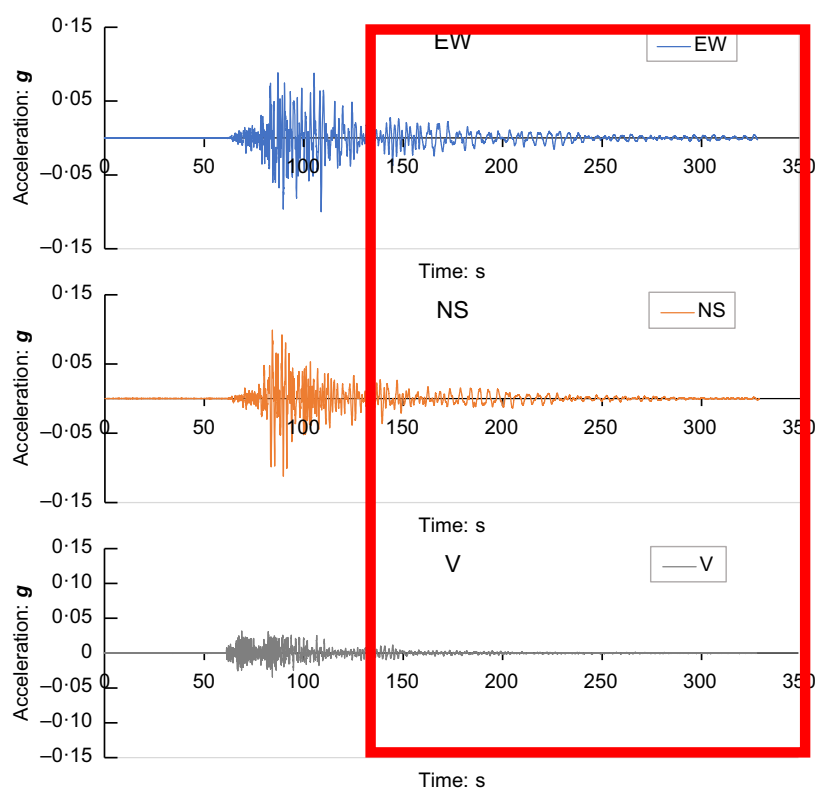

Fig. 29. Seismographs from Aux station, within the urbanised lake zone, Puebla earthquake, second phase beating shown after 140 s time mark

described by O'Riordan et al. (2018b), adjusted for strength and stiffness rate effects and with non-Masing damping. The Mat_Hysteretic soil model is composed of many concentric elastic-perfectly plastic yield surfaces, each of which describes a portion of the material's shear behaviour. Shear strain rate effects were incorporated into the soil model by way of visco-plastic adjustments to the size of the yield surfaces (i.e. higher strain rates correspond to larger yield surfaces). Similarly, non-Masing damping was incorporated by adjusting the size of the various yield surfaces in order to produce narrower hysteretic loops following the accumulation of damage strain. In this case, damage strain was defined as the accumulation of shear strains when shear stress exceeds approximately $70 \%$ of the shear strength. The baseline shear wave velocity against depth data for SCT are given in Table 3. The SCT site has been studied by many and there are several shear wave profiles published. As an example, the shear wave velocities implied by Martinez-Hernandez et al. (2002) are included, together with the profile by Ovando-Shelley et al. (2007) that Garini et al. (2020) used and which is also used as a baseline for calibration against the vertical array data.

It was found, for the earthquakes listed in Table 2 and using the vertical array data, that unadjusted, $V_{\mathrm{s}}+0 \%$ values resulted in substantial overestimation of peak spectral accelerations, as illustrated by Garini et al. (2020) in their Fig. 11(a) for the Puebla event. Conversely, at $V_{\mathrm{s}}+30 \%$ the peaks were reduced and found at periods that were too low. Mexico City clay behaviour under dynamic load presents a particular challenge as stiffness and strength depend upon the highly variable diatom content, the high salinity in the pore water in the eastern half of the lake-bed deposits and the continuing reduction in void ratio caused by groundwater extraction. It was found that the best match to the recorded data at depth and at the ground surface was found if the published shear wave velocities for the clay layers at both the CAO and SCT sites were increased by $15 \%$. This increase is likely to be due to a combination of thixotropic and ageing effects.

In performance-based seismic design, in which a nearcomplete soil-structure interaction model is subjected to selected earthquake motions scaled according to the ground 

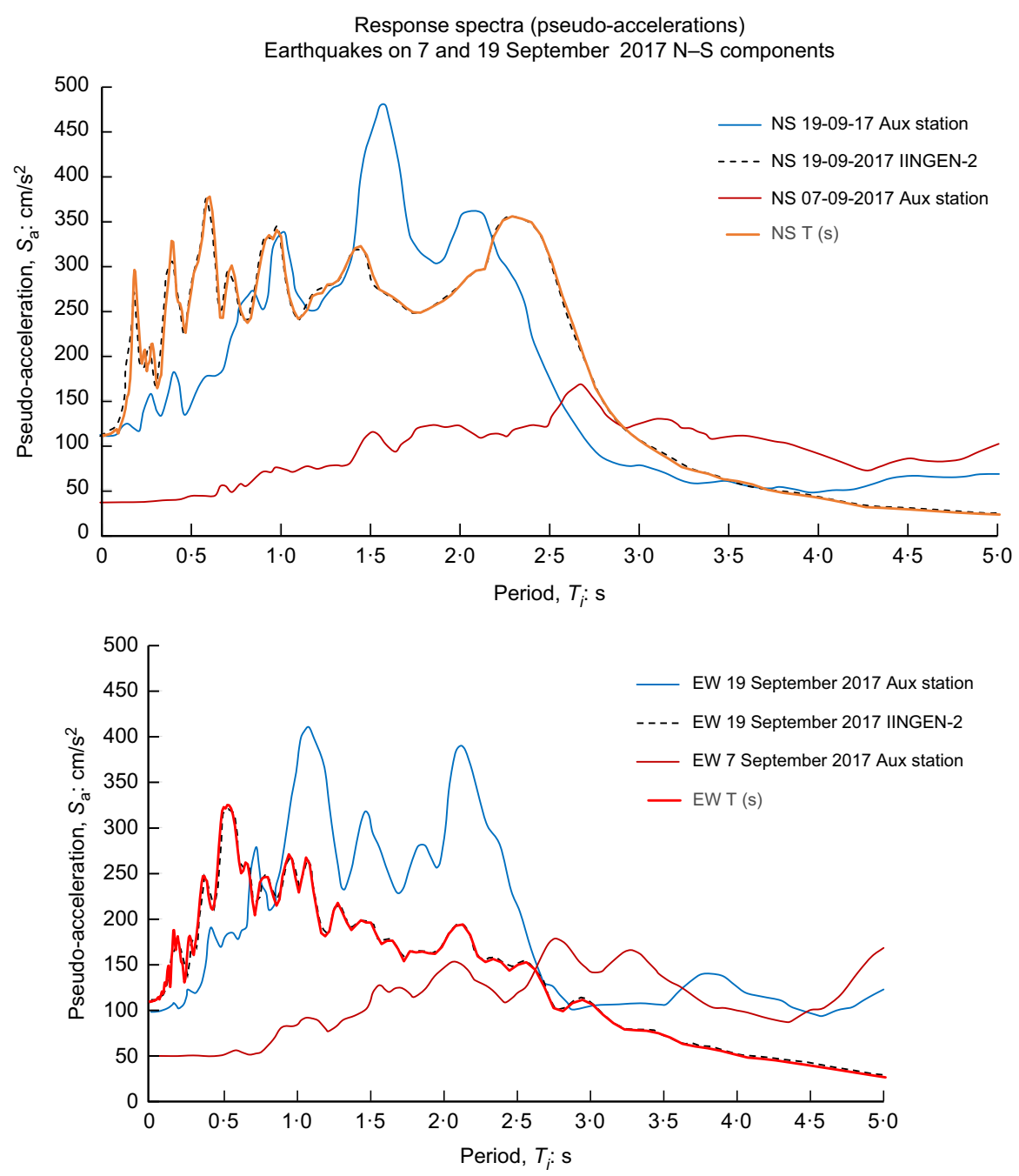

Fig. 30. Pseudo-acceleration spectra for Aux and IINGEN-2 recording stations, Chiapas and Puebla events in 2017 (after II-UNAM, 2017)

motion hazard analysis (e.g. ASCE 7-16 (ASCE, 2016), chapters 19 and 21), it is important to establish carefully the strength and stiffness of the foundation soils at the appropriate loading rate. If the foundation soils are modelled too softly then the seismic energy delivered to the foundation and superstructure can be significantly underestimated and the demand on superstructure components will likewise be underestimated and potentially under-sized. Thus a 15\% uplift on shear wave velocity has an important effect upon design and subsequent back-analysis.

Unfortunately, the CAO vertical array did not function during the Puebla earthquake and only the ground surface seismograph at SCT functioned. However, reuse of the $V_{\mathrm{s}}+15 \%$ shear wave profile from earlier studies (without any alteration) resulted in a successful simulation of the seismograph record at SCT, shown here in Figs 34 and 35. Notably the computed strong motion duration is close to the measured record, in contrast with the $40 \mathrm{~s}$ time history computed by Garini et al. (2020) in their Fig. 11(c); however, it was not able to replicate the time history between time marks 110 and $130 \mathrm{~s}$ for the EW (N90E) component.

Figure 35 compares the acceleration spectra with and without the increased shear wave velocity. The computations at $V_{\mathrm{s}}+0 \%$ show a spectral content that is very different to the measured values. The reasons for this are not entirely clear; however, it is suspected that this may be either due to an underestimation of the operational shear strength in the numerical model at $V_{\mathrm{s}}+0 \%$ or to the particular spectral content of the $\mathrm{CU}$ record in this case. Either way, it would be interesting to know the soil parameters that Garini et al. (2020) used in their one-dimensional (1D) analysis at the SCT site: were they close to those shown in Table 2 for $V_{\mathrm{s}}+0 \%$ ?

It is observed that it is important to simulate earthquake records using three-dimensional (3D) finite-element software equipped with appropriate, rate-dependent soil parameters and subject to multi-directional shaking. Nevertheless, it is recognised that $1 \mathrm{D}$ simulations can be carried out efficiently for academic purposes, as has been displayed by Garini et al. (2020). After careful calibration of the 'far-field', or in the Mexico City case, the urban city block characteristics surrounding the motion recording station, new buildings and other installations can then be inserted into the analysis with confidence and a rigorous performance-based design can proceed.

\section{Authors' reply}

The authors thank the discussers for their interest in the published paper, and the valuable additional information they are providing. The motions recorded in two accelerograph stations, Aux and IINGEN2 (located, respectively, at the edge of the urbanised part of the city and about $5 \mathrm{~km}$ beyond the city limits at the site of the under-construction new airport, both on the lake bed of Texcoco Lake), along 


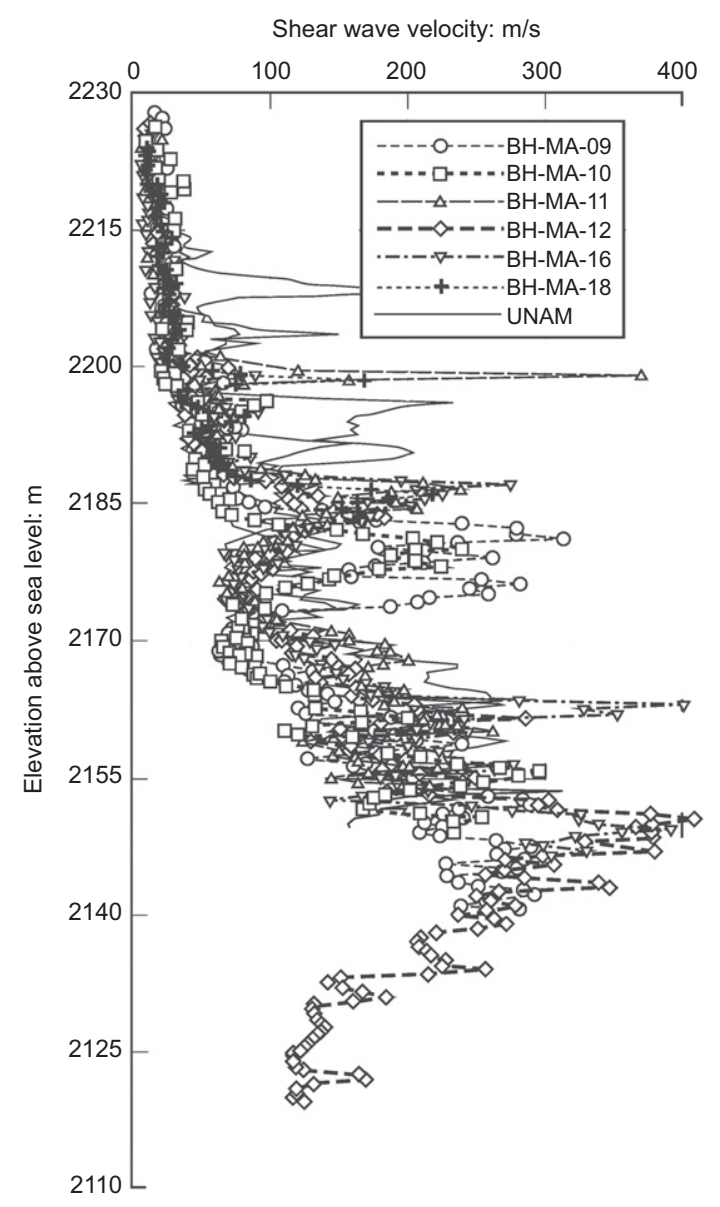

Fig. 31. Variation in shear wave velocity at IINGEN-2 site location

with the analysis of these records, offer indeed an important contribution by the discussers on the possible causes of the long duration of records and the 'beating' noted in the long-period coda in some of the records.

In the published paper the authors showed the following.

(a) One-dimensional wave propagation through the soft soil layers of the Mexico City clay can explain the most severe peaks in the response spectra of the recorded lake-bed motions ('soil amplification'). In fact, even an elementary wave-propagation analysis of soil deposits idealised as uniform can explain these peaks - an analysis suitable for teaching in the classroom. But this was hardly a new finding: numerous publications, some even before the dramatic 1985 event, had revealed the resonance phenomena between the incoming seismic waves and the soil stratum that led to huge amplification peaks at periods of 2, 3 and $4 \mathrm{~s}$, depending primarily on the thickness of the soft soils. The paper has cited several such publications (including Whitman, 1986; Flores et al., 1987; Sánchez-Sesma, 1987; Seed et al., 1987, 1988; Lermo et al., 1988; Sánchez-Sesma et al., 1988; Singh et al., 1988; Rosenblueth \& Ovando 1991; Lermo \& Chavez-Garcia, 1994; Faccioli et al., 1996; Ovando-Shelley et al., 2007; Osorio et al., 2009).

(b) However, the peak values at this ('resonant') period show a substantial variability - from earthquake to earthquake, from EW to NS direction, and from using CU or TACY as reference rock motions. Since amplification increases with decreasing damping, one would expect increased peak values with the weaker motions, but this was not always the case - which is evidence of other contributing
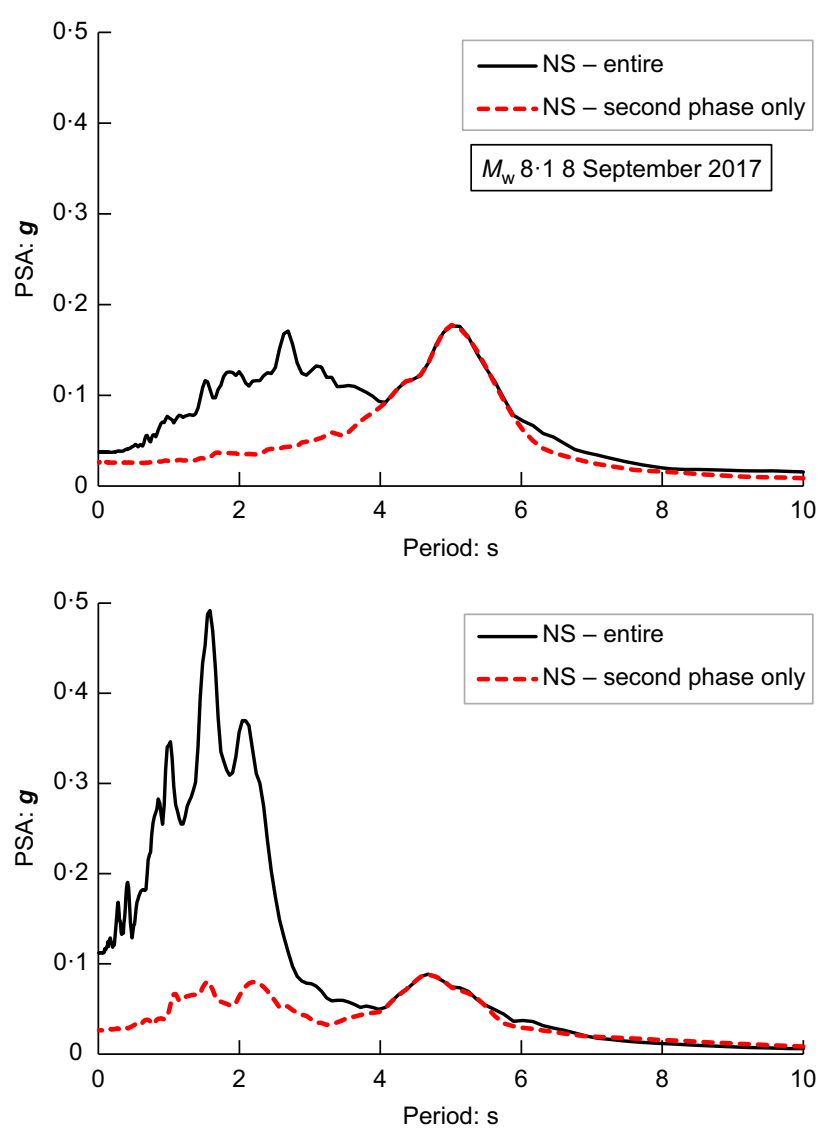

Fig. 32. Pseudo-spectral acceleration (PSA) analysis showing separate beating phase at a dominant period of about $5 \mathrm{~s}$ for both Chiapas and Puebla 2017 events
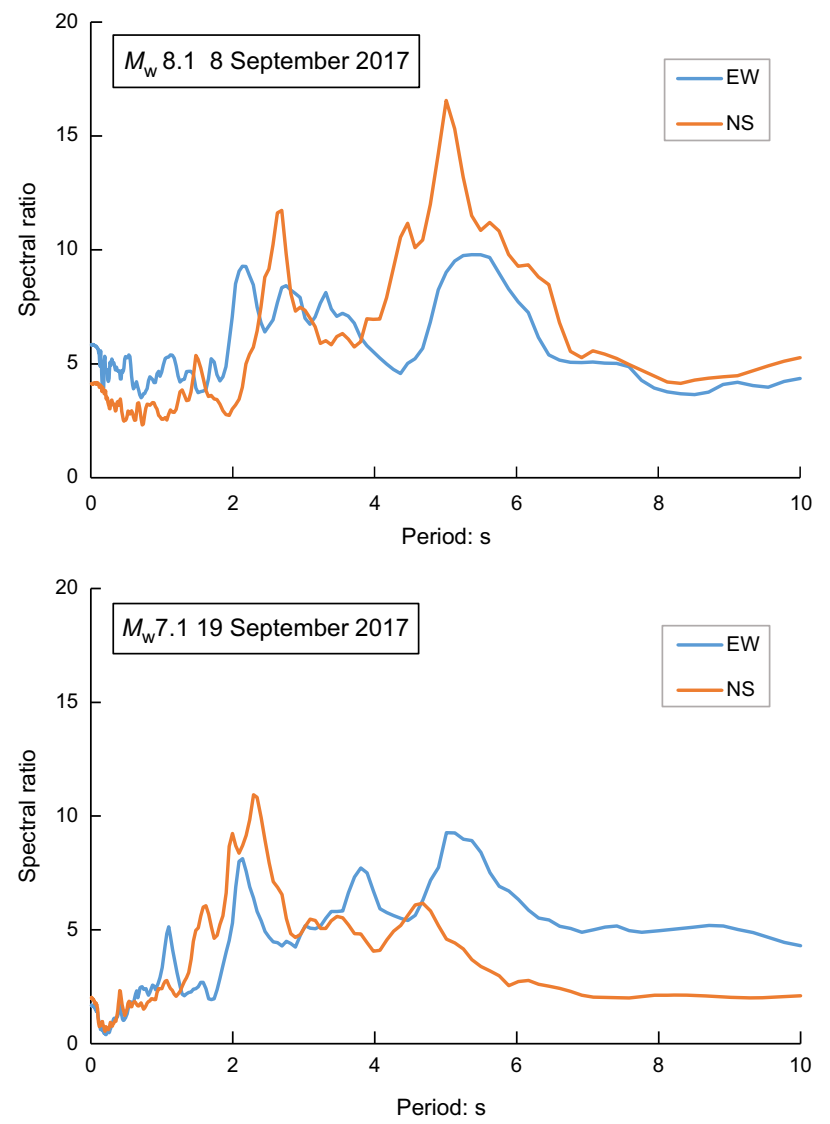

Fig. 33. Spectral amplification at the Aux site for the Chiapas and Puebla 2017 events relative to $\mathrm{CU}$ site records 
factors, in addition to the unavoidable randomness of the earthquake phenomenon. Clearly, earthquake reality is often too complicated to be deterministically and rigidly specified. Nevertheless, from an engineering point of view, a value of peak amplification at a resonance of about 10 to 12 for earthquake motions with peak ground acceleration (PGA) in the rock outcrop of the order of $0 \cdot 05 \mathrm{~g}$ or a little less could be used as a reasonably conservative estimate that would suffice, especially for inelastic structural analysis in most earthquakes.

(c) The two-dimensional (2D) wave propagation effects arising from the Rayleigh and Love waves generated at the edges of the Mexico City valley may have contributed to the long duration of the records and the presence of several 'beating' cycles noticed, especially in some weak motions near the middle of the valley ('basin' effect). Three-dimensional wave propagation might also have aggravated the differences between the two horizontal components of the records, although $3 \mathrm{D}$ analyses for a valley so huge in area is a daunting (hardly feasible) task. Again, several earlier studies had explored the 'basin' effects for Mexico City. Some of those are cited in the paper. Specifically, Sánchez-Sesma et al. (1986), Bard et al. (1988), Campillo et al. (1988), Barker et al. (1996), Ramos-Martinez et al. (1997), Chavez-Garcia \& Salazar (2002) and Cardenas-Soto \& Chavez-Garcia (2004), among others, have persuasively argued that $2 \mathrm{D}$ modelling of the broader and deeper basin with its lateral heterogeneities would lead to improved agreement between recorded and computed accelerograms.

Table 2. Earthquake records considered for back-analysis

\begin{tabular}{l|r|r|c}
\hline Event date & $\begin{array}{c}\text { Epicentral } \\
\text { distance: } \\
\mathrm{km}\end{array}$ & $\begin{array}{c}\text { Focal } \\
\text { depth: } \\
\mathrm{km}\end{array}$ & $\begin{array}{c}\text { Magnitude, } \\
M_{\mathrm{W}}\end{array}$ \\
\hline \multicolumn{2}{|c}{ Motions considered for CAO site } \\
24 October 1993 & 310 & 26 & $6 \cdot 6$ \\
23 May 1994 & 215 & 23 & $5 \cdot 6$ \\
9 October 1995 & 591 & 5 & $8 \cdot 0$ \\
11 January 1997 & 446 & 16 & $7 \cdot 1$ \\
21 June 1999 & 306 & 54 & $6 \cdot 3$ \\
30 September 1999 & 438 & 40 & $7 \cdot 4$ \\
19 September 1985* & 420 & 22 & $8 \cdot 0$ \\
Motions considered for SCT site & 325 & 22 & $7 \cdot 3$ \\
14 September 1995 & 220 & 60 & $6 \cdot 9$ \\
15 June 1999 & 425 & 22 & $8 \cdot 0$ \\
19 September 1985* & & \\
\hline
\end{tabular}

*No downhole array data for the 19 September 1985 Michoacán earthquake at the CAO and SCT stations; the recording from the CU station was used with a scale factor of 1.2 and 2.0 for CAO and SCT, respectively, to account for the difference in site conditions; the epicentral distance to the $\mathrm{CU}$ site was $394 \mathrm{~km}$. (d) Tall buildings in double resonance with the soil stratum and the incoming seismic waves transfer some of their vibrational energy back into the ground: surface waves emanating from the foundation spread outward and influence ('contaminate') the free-field records ('soil- building-soil interaction' (SBSI)). In a way, this influence is not very different from that of the waves generated at the edges of a basin, causing the appearance of high-period 'beating' cycles in the latest part of the motion and thereby increasing its duration. In the simple FE analysis, some of these effects could indeed be inferred as real, although they were not very distinguishable. And quasi-elastic soil behaviour is a prerequisite for this feedback to have a measurable effect (since otherwise a large hysteretic damping will significantly restrict wave transmission (see Gelagoti et al., 2012)). But with the motions recorded on the free field of a dense city area, the presence of several tall buildings of similar height (and hence of similar natural frequency) could have a more substantial effect. Several studies, including Wirgin \& Bard (1996), Meli et al. (1998), Cardenas et al. (2000), Gueguen et al. (2000, 2002) and Tsogka \& Wirgin (2003), have presented analytical evidence of the significance of the presence and vibration of a number of buildings (an urbanised city) on the motion at the ground surface of a soft, elastic stratum underlain by rock.

In any case, the conclusion of the study is that 1D soil amplification is quite successful in explaining the phenomena, with 2D (or 3D) 'basin' and 'city' effects perhaps also playing a secondary role.

The first part of the discussers' contribution addresses this latter topic: the 'city' (or, in their words, the 'urbanised area') effect on the recorded free-field motions. By examining the accelerograms of the aforementioned two sites in the 19 September 2017 (Puebla) earthquake, they notice in relation to the Aux (in an urbanised area)

(a) that it has a longer duration than IINGEN (in a green-field area)

(b) beyond about the first $70 \mathrm{~s}( \pm)$ of strong motion, its coda (called the second phase) contains high-period oscillations, perhaps resembling a beating style. (Most probably the Chiapas record, having originated from a larger magnitude event and at longer distance would show the 'beating' cycles more conspicuously.)

Moreover, they compute the response spectra of the entire NS component of the accelerogram and of its coda cut-off part (the second phase). In Fig. 32, it is clearly seen that for periods exceeding $4 \mathrm{~s}$ the two spectra completely match. This is indeed a very interesting observation for which the discussers should be commended.

Table 3. SCT site: variation of shear wave velocity with depth

\begin{tabular}{|c|c|c|c|c|c|c|c|}
\hline \multicolumn{2}{|c|}{ Depth: $\mathrm{m}$} & \multirow[t]{2}{*}{ Soil type } & \multirow{2}{*}{$\begin{array}{l}\gamma: \mathrm{kN} / \mathrm{m}^{3} \\
\text { (Martinez- } \\
\text { Hernandez } \\
\text { et al., 2002) }\end{array}$} & \multirow{2}{*}{$\begin{array}{l}G: \text { MPa } \\
\text { (Martinez- } \\
\text { Hernandez } \\
\text { et al., 2002) }\end{array}$} & \multicolumn{3}{|c|}{ Shear wave velocity, $V_{\mathrm{s}}: \mathrm{m} / \mathrm{s}$} \\
\hline Top & Base & & & & $\begin{array}{c}V_{\mathrm{s}}+0 \% \text { calculated from } \\
\text { Ovando-Shelley et al. (2007) }\end{array}$ & $\begin{array}{l}\text { Back-calculated } \\
\text { from } G\end{array}$ & $\begin{array}{c}V_{\mathrm{s}}+15 \% \\
\text { (clay layers only) }\end{array}$ \\
\hline 0 & 4 & Sand & $15 \cdot 84$ & $6 \cdot 7$ & 100 & 64 & 100 \\
\hline 4 & 9 & Clay & $11 \cdot 88$ & $4 \cdot 3$ & 55 & 60 & 64 \\
\hline 9 & 14 & Clay & $11 \cdot 88$ & $4 \cdot 3$ & 55 & 60 & 64 \\
\hline 14 & 20 & Clay & $12 \cdot 28$ & $12 \cdot 3$ & 55 & 99 & 64 \\
\hline 20 & 31 & Clay & $12 \cdot 28$ & $12 \cdot 3$ & 75 & 99 & 86 \\
\hline 31 & 36 & Sandy silt & $15 \cdot 81$ & 254 & 300 & 397 & 300 \\
\hline 36 & 40 & Clay & $13 \cdot 54$ & $40 \cdot 58$ & 150 & 171 & 173 \\
\hline
\end{tabular}



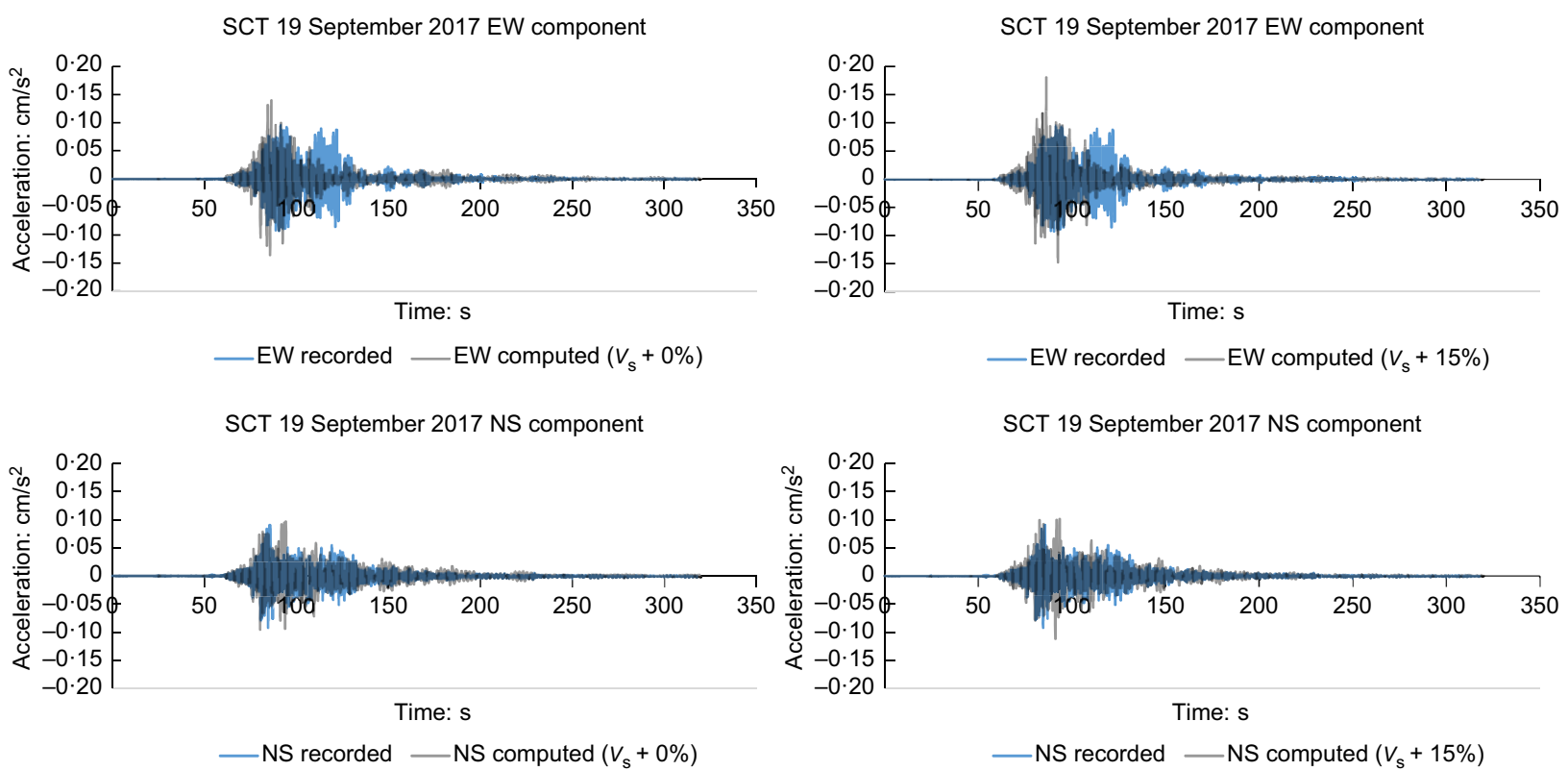

Fig. 34. Comparison of simulated and recorded time histories for the 19 September 2017 Puebla event at the SCT site; results are shown both for baseline $\left(V_{\mathrm{s}}+0 \%\right)$ and $15 \%$ enhanced $\left(V_{\mathrm{s}}+15 \%\right)$ profiles: (a) EW component baseline; (b) EW component enhanced; (c) NS component baseline; (d) NS component enhanced
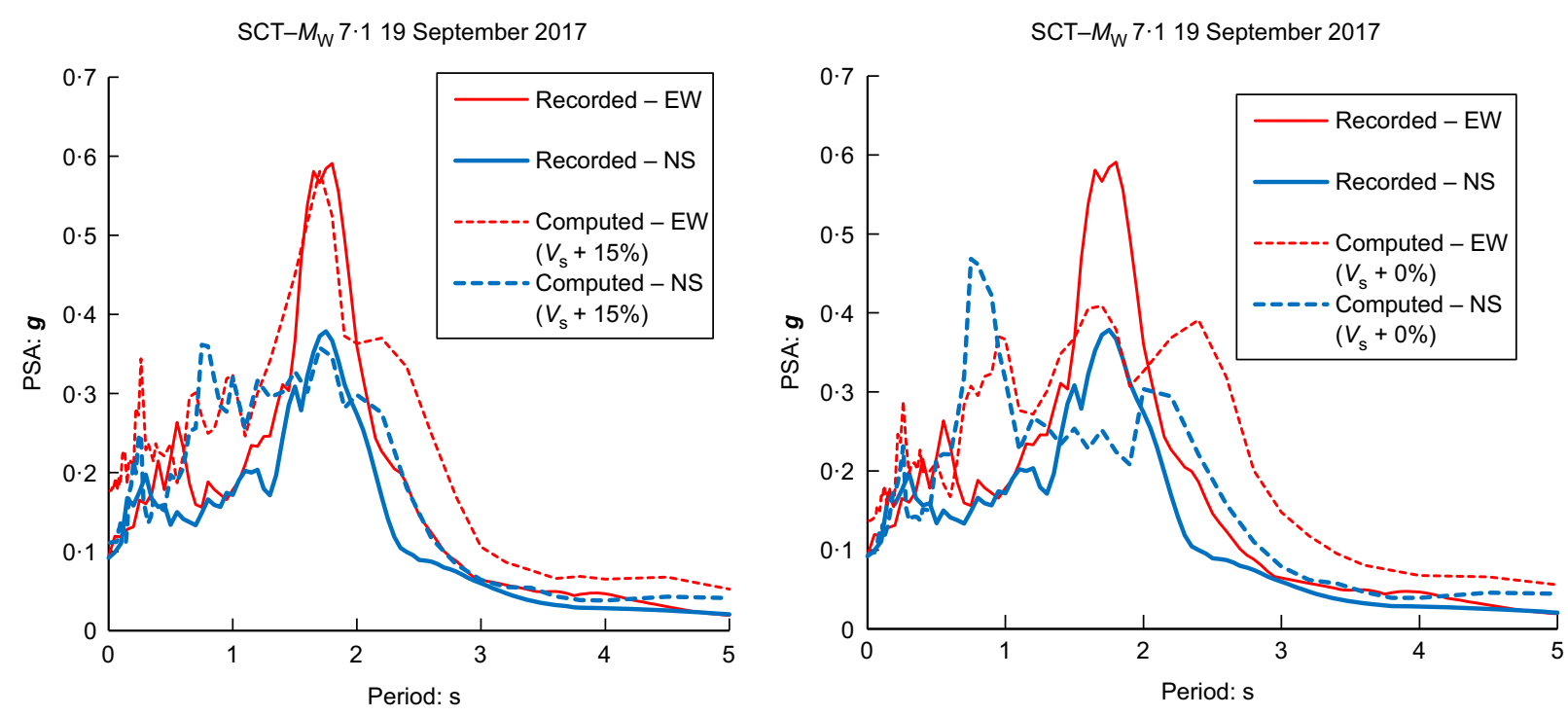

Fig. 35. Spectral analysis for the SCT site, Puebla 2017 earthquake, computed using CU station input (after O'Riordan et al., 2018a)

The obvious implication is that the long-period wave components of the recorded motion which are responsible for the high values beyond $T=4 \mathrm{~s}$ are all appearing in this late second phase. This is an undisputable fact. The question is: what are the causes of this phenomenon, which is attributed by the discussers solely to the 'city' effect. Undoubtedly, this is a distinct possibility. But before finalising such a conclusion, it is reasonable to first exclude the contributions of $1 \mathrm{D}$ and $2 \mathrm{D}$ (or 3D) wave propagation phenomena (i.e. the 1D amplification and the basin effects).

To help somewhat in this direction, the authors analyse the record of IINGEN in the Puebla earthquake in the fashion of the discussers' plots for the Aux records. Figs 36 and 37 plot, at the top, the time histories of the two components (NS and EW, respectively) of IINGEN but with the frame containing the coda also drawn. Notice that beating cycles are fairly distinguishable in this record as well, perhaps more conspicuously than in Aux. But, admittedly, they are of relatively smaller amplitude and shorter period of oscillation than those in the Aux record. The bottom plots of Figs 36 and 37 compare the response spectra of the entire motions and of their coda. Now, again the NS-component-derived (entire and coda) spectra nearly match at, approximately, $T>3 \mathrm{~s}$, but not as perfectly as in the case of Aux. (The matching is not very good for the EW component.) And the IINGEN spectra attain in the coda regions small values, monotonously declining with period. What can be concluded from these comparisons?

(a) Even without 'city' effects (IINGEN), beating cycles do indeed develop in the motions' coda.

(b) The relative amplitude of the coda cycles is stronger and of longer period in Aux (in the city) than in IINGEN (in free ground). 


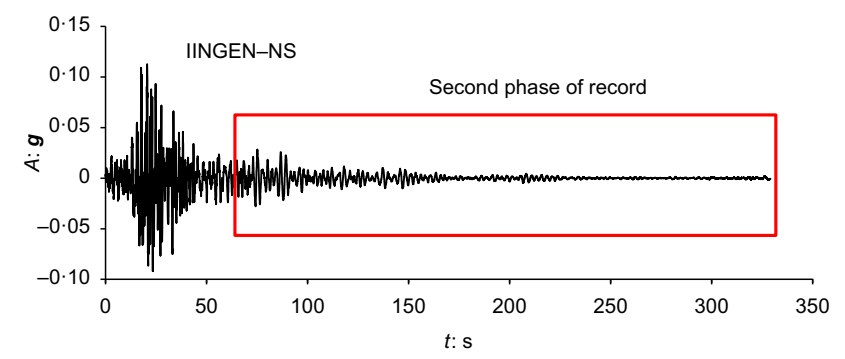

(a)

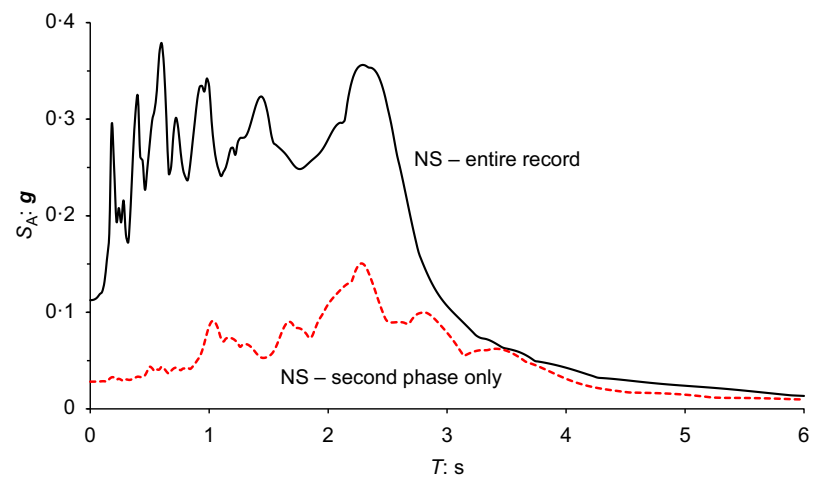

(b)

Fig. 36. (a) The NS accelerogram from IINGEN (outside the urbanised zone), with its coda being time framed; (b) the spectra of the entire motion and its coda

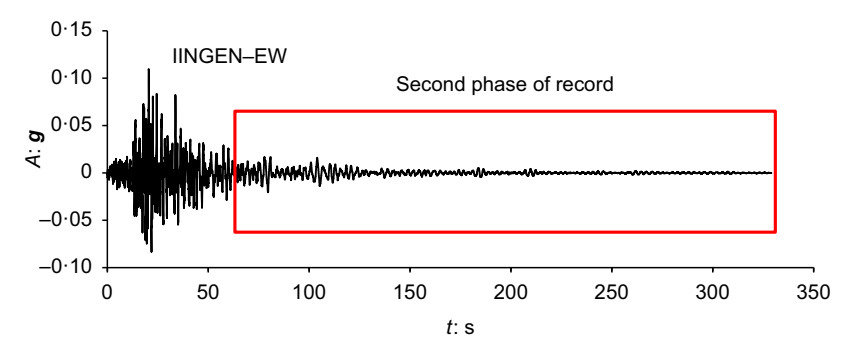

(a)

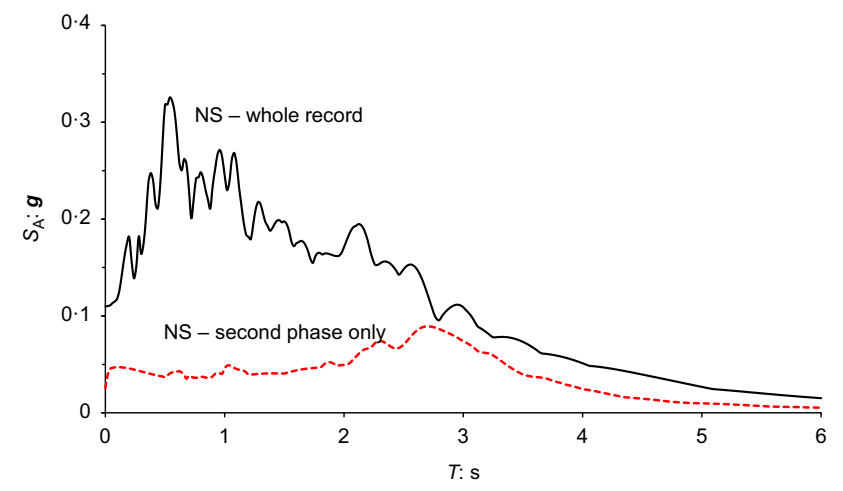

(b)

Fig. 37. (a) The EW accelerogram from IINGEN (outside the urbanised zone), with its coda being time framed; (b) the spectra of the entire motion and its coda

The causes of these observations, however, are not quite evident without further analysis. Without the soil profile of Aux, it is not possible to judge the role of 1D soil amplification. The discussers point out that the IINGEN station is on stiffer soil. While this might indeed be a cause of the shorter-period coda of the IINGEN motion, the comparison of response spectra in Fig. 30(a) tells a slightly different and more complex story: the IINGEN dominant period $T \approx 2.5 \mathrm{~s}$ is larger, not smaller, than that of Aux
( $T \approx 2 \cdot 2 \mathrm{~s}$ ). Yet, for $T>3$ or $3.5 \mathrm{~s}$ the Aux spectra increase with period or remain about constant, whereas the IINGEN spectra rapidly decline. Hence, there may be a contribution of 'city' effects as the discussers suggest.

For an estimate of the potential 'city' effect, however, one needs to know the soil profile (only crudely hypothesised for Aux), and to estimate the density of the buildings surrounding the station, the height of the various buildings and their fundamental periods (Gueguen et al., 2002). Of critical importance is the proximity of the fundamental periods of a particular building and the soil. As it was demonstrated in the original paper in Fig. 24, the effect (feedback) of a vibrating building on the nearby free field is conspicuous only when the two fundamental periods coincide. The discussers present only a small part of such information (understandably of course, due to the limitations of a discussion). They report the existence of $5.9 \mathrm{~m}$ high two-storey buildings in the city block, of $0.27 \mathrm{~s}$ estimated fundamental period. And for the estimated $40 \mathrm{~m}$ thick soft soil, its fundamental period is correctly taken as equal to $4.0 \mathrm{~s}$ (based on the dominant spectral value). It is not evident how such buildings and their high-frequency oscillations may have affected the coda of the records to an appreciable degree. The discussers mention as evidence the large value of Gueguen's 'kinematic energy ratio' - the estimation of which, however, requires all the above-mentioned knowledge. Their points may indeed be valid, but they are encouraged to provide all the necessary information to fully substantiate their hypothesis (if not in this discussion, then in a new paper; it would be valuable).

Nevertheless, 'basin' effects cannot be ruled out without careful analysis. They have been shown to lead to lengthening of the surface motions with beating cycles, as well. Such analyses would be a formidable task, unless some gross simplification is put forward, as in the paper.

Nor can one ignore the resonance in 1D amplification, which, for the soft soil of Mexico City and weak (hence low damping) motions, will not allow termination of the surface signal just as soon as the rock base excitation ends. It is worth recalling the explanation by Singh \& Ordaz (1993) of why long-duration coda with beating cycles in the 1985 earthquake were observed only in the records of the lake zone: the hilly zone ('rock') records had inadvertently terminated at about $60 \mathrm{~s}$ due to the insensitivity of the accelerographs at that time (1985) to small accelerations. Based on records (of instruments with improved sensitivity) from later earthquakes (some of which were examined in the paper), Singh and Ordaz convincingly concluded that, if the instruments had been sensitive enough, they would also have recorded longer coda in CU and TACY. With such longer input motion, 1D analysis could have at least partly explained the long duration and beating style of the SCT and CAO motions.

The authors also recall another possibility applicable for tall buildings: coupled torsional and translational modes of vibration can generate several beating cycles of motion in the structure, as evidenced in several cases from California, Japan and Italy (Celebi, 2007, 2018; Rinaldis et al., 2018). It seems plausible that some of these oscillations reach the foundation and are then transmitted into the soil in the form of Love (SH) waves, thereby contaminating the free-field records. This phenomenon could also be characterised as the SBSI or 'city' effect. The authors do not know if such tall buildings exist near the Aux site; if they do, this may offer additional support to the discussers' hypothesis.

In the second part of the discussion, two borehole accelerographs (at $-25 \mathrm{~m}$ in SCT and $-60 \mathrm{~m}$ in CAO) and some of their recordings after 1993 are reported. They are utilised to obtain numerically the motions at the top and 
their response spectra. Two different $\mathrm{S}$ wave velocity profiles are considered, named $\left(V_{\mathrm{S}}+0 \%\right)$ and $\left(V_{\mathrm{S}}+15 \%\right)$. They are compared with the corresponding records to show that the latter stiffer profile leads to a better accord with reality. It would have been of great interest to present the borehole accelerograms (and their response spectra), in order to compare their coda with those of the surface motions.

The authors cannot agree with the terminology used by the discussers, describing their analyses as 'three-dimensional'. They use a 1D soil profile (the same as in the paper) and subject it to bi-directional shaking. In view, however, of the unquestionably linear clay response, especially during the small-intensity events (surface PGA $<0 \cdot 1$ g), the coupling between the two directions of motion would be quite small. So, their analyses are essentially also 1D (or, to be more accurate, $\left.1 \frac{1}{2} \mathrm{D}\right)$. The plasticity-based model they outline is certainly of great value, but its use in this specific case offers few additional insights. Even a 2D analysis requires discretisation of a broader part of the valley, or the building on top. The published paper did attempt two types of such analyses, although admittedly with very crude geometric and material simplifications.

In conclusion, the discussers are to be thanked for providing new important information, offering new insights, and triggering renewed thinking with respect to some challenging and controversial aspects of the Mexico City earthquakes. The authors look forward to seeing in the near future a (more complete) publication on this subject, taking into consideration some of the comments.

\section{ACKNOWLEDGEMENTS}

The authors of this discussion thank Professor Efrain Ovando-Shelley of the Instituto de Ingeneria (II) of UNAM, Mexico City for permission to publish the seismograph records for IINGEN-2 and Aux stations and Professor J. Mayoral of II-UNAM for access to the Mexican strong motion database.

\section{REFERENCES}

Alcántara, L., Quaas, R., Pérez, C., Ayala, M., Macías, M. A., Sandoval, H., Javier, C., Mena, E., Andrade, E., González, F., Rodríguez, E., Vidal, E., Murguía, L., Luna, M., Espinoza, J. M., Cuellar, A., Camarillo, L., Ramos, S., Sánchez, M., Guevara, E., Flores, J. A., López, B., Ruiz, R., Pacheco, J., Ramírez, M., Aguilar, J., Juárez, J., Vera, R., Gama, A., Cruz, R., Hurtado, F., Martín del Campo, R. \& Vera, R. (2000). Mexican strong motion database, CD-rom v2. Mexico City, Mexico: Mexican Society of Seismic Engineering.

ASCE (American Society of Civil Engineers) (2017). ASCE 7-16: Minimum design loads and associated criteria for buildings and other structures. Reston, VA, USA: American Society of Civil Engineers.

Bard, P. Y., Campillo, M., Chavez-Garcia, F. J. \& Sanchez-Sesma, F. J. (1988). The Mexico Earthquake of September 19, 1985-a theoretical investigation of large- and small-scale amplification effects in the Mexico City Valley. Earthq. Spectra 4, No. 3, 609-633.

Barker, J. S., Campillo, M., Sanchez-Sesma, F. J., Jongmans, D. \& Singh, S. K. (1996). Analysis of wave propagation in the Valley of Mexico for a dense array of seismometers. Bull. Seismol. Soc. Am. 86, No 6, 1667-1680.

Campillo, M., Bard, P. Y., Nicollin, F. \& Sanchez-Sesma, F. J. (1988). The incident wave field in Mexico City during the great earthquake and its interaction with the deep basin. The Mexico Earthquake of September 19, 1985. Earthq. Spectra 4, No. 3, 591-608.

Cardenas-Soto, M. \& Chavez-Garcia, F. J. (2004). The wavefield in Mexico City as seen in the vertical arrays. Proceedings of the 13 th world conference on earthquake engineering, Vancouver, BC, Canada, paper no. 2428.
Cardenas, M., Bard, P. Y., Gueguen, P. \& Chavez-Garcia, F. J. (2000). Soil-structure interaction in Mexico City. Wave field radiated away from Jalapa building: data and modelling. Proceedings of the 12th world conference on earthquake engineering, Auckland, New Zealand, paper no. 0385.

Celebi, M. (2007). Beating effect identified from seismic responses of instrumented buildings. In Structures congress 2007: new horizons and better practices (ed. R. Lyons), https://doi.org/10. 1061/40946(248)14. Reston, VA, USA: American Society of Civil Engineers.

Celebi, M. (2018). Quantifying the effect of beating inferred from recorded responses of tall buildings. Proceedings of the 16th European conference on earthquake engineering, Thessaloniki, Greece, paper ID: 10171.

Chavez-Garcia, F. J. \& Salazar, L. (2002). A model to explain site response at Mexico City. Bull. Seismol. Soc. Am. 92, No. 8, 3087-3101.

Faccioli, E., Paolucci, R. \& Vanini, M. (1996). Studies of site response and soil-structure interaction effects in a tall building in Mexico City. Proceedings of the eleventh world conference on earthquake engineering, Acapulco, Mexico, paper no. 569.

Flores, J., Novaro, O. \& Seligman, T. H. (1987). Possible resonant effect in the distribution of earthquake damage in Mexico City. Nature 326, No. 6115, 783-785.

Garini, E., Anastasopoulos, I. \& Gazetas, G. (2020). Soil, basin and soil-building-soil interaction effects on motions of Mexico City during seven earthquakes. Géotechnique 70, No. 7, 581-607, https://doi.org/10.1680/jgeot.18.P.314.

Gelagoti, F., Kourkoulis, R., Anastasopoulos, I. \& Gazetas, G. (2012). Nonlinear dimensional analysis of trapezoidal valleys subjected to vertically propagating SV waves. Bull. Seismol. Soc. Am. 102, No. 3, 999-1017.

Gueguen, P., Bard, P. Y. \& Oliveira, C. S. (2000). Experimental and numerical analysis of soil motions caused by free vibrations of a building model. Bull. Seismol. Soc. Am. 90, No. 6, 1464-1479.

Gueguen, P., Bard, P. Y. \& Chavez-Garcia, F. (2002). Site-city seismic interaction in Mexico City-like environments: an analytical study. Bull. Seismol. Soc. Am. 92, No. 2, 794-811.

II-UNAM (Instituto de Ingeniería, National Autonomous University of Mexico) (2017). Initial observations and preliminary recommendations on structural aspects in relation to the effects of the earthquakes of September 2017 on the construction of NAICM, Report to Grupo Aeroportuario de la Ciudad de Mexico. Mexico City, Mexico: II-UNAM (in Spanish).

Kumar, P., Ellison, K., Paul, N., Lee, J., Almufti, I. \& Stanton, K. (2017). Is there a basin effect in Mexico city? Validation of three urban lakebed sites using nonlinear site response analysis provides the clue. In Proceedings from 3rd international conference of performance-based design in earthquake geotechnical engineering (PBD-III). London, UK: International Society for Soil Mechanics and Geotechnical Engineering (ISSMGE). See https://www.issmge.org/uploads/publications/ 59/57/pbdiiiPaper251.pdf (accessed 18/01/2021).

Lermo, J., Rodriguez, M. \& Singh, S. K. (1988). Natural period of sites in the Valley of Mexico from microtremor measurements and strong motion data. The Mexico Earthquake of September 19, 1985. Earthq. Spectra 4, No. 4, 805-814.

Lermo, J. \& Chavez-Garcia, F. J. (1994). Site effect evaluation at Mexico City: dominant period and relative amplification from strong motion and microtremor records. Soil Dyn. Earthq. Engng 13, No. 6, 413-423.

Martinez-Hernandez, F. G., Taboada-Urtuzuastegui, V. M., Elgamal, A. W. \& Romo, M. P. (2002). Linear analysis to evaluate dynamic soil properties at SCT site in Mexico city. In Parametres de calcul geotechnique (ed. J.-P. Magnan), pp. 181-188. Paris, France: Presses de l'ENPC/LCPC.

Mayoral, J. M., Asimaki, D., Tepalcapa, S., Wood, C., Roman de la Sancha, A., Hutchinson, T., Franke, K. \& Montalva, G. (2019). Site effects in Mexico City basin: past and present. Soil Dyn. Earthq. Engng 121, 369-382.

Meli, R., Faccioli, E., Muria-Vila, D., Quass, R. \& Paolucci, R. (1998). A study of site effects and seismic response of an instrumented building in Mexico City. J. Earthq. Engng 2, No. 1, 89-111. 
O'Riordan, N., Almufti, I., Lee, J., Ellison, K. \& Motamed, R. (2018a). Site response analysis for dynamic soil-structure interaction and performance-based design. Proc. Instn Civ. Engrs - Geotech. Engng 172, No. 1, 76-86, https://doi.org/ 10.1680/jgeen.17.00209.

O'Riordan, N., Kumar, S., Ciruela-Ochoa, F. \& Canavate-Grimal, A. (2018b). Estimation and calibration of input parameters for Lake Texcoco Clays, Mexico City. In Proceedings of numerical methods in geotechnical engineering $I X$ (eds A. S. Cardoso, J. L. Borges, A. T. Gomes, J. C. Marques and C. S. Vieira), vol. 1, pp 163-172. London, UK: Taylor \& Francis.

Osorio, L., Mayoral, J. M. \& Romo, M. P. (2009). Characterization of the seismic environment prevailing at Texcoco Lake, Mexico. In Proceedings of the 17th international conference on soil mechanics and geotechnical engineering (eds M. Hamza, M. Shahien and Y. El-Mossallamy), pp. 1008-1011. Rotterdam, the Netherlands: Millpress.

Ovando-Shelley, E., Romo, M. P. \& Ossa, A. (2007). The sinking of Mexico City: its effects on soil properties and seismic response. Soil Dyn. Earthq. Engng 27, No. 4, 333-343.

Ramos-Martínez, J., Chávez-García, F. J., Romero-Jiménez, E., Rodríguez-Zúñiga, J. L. \& Gómez-González, J. M. (1997). Site effects in Mexico City: constraints from surface wave inversion of shallow refraction data. J. Appl. Geophys. 36, No. 4, 157-165.

Rinaldis, D., Buffarini, G. \& Clemente, P. (2018). Beating effect in an historical building identified from seismic responses. Proceedings of the 16th European conference on earthquake engineering, Thessaloniki, Greece, paper ID: 10919.

Rosenblueth, E. \& Ovando, E. (1991). Geotechnical lessons learned from Mexico and other recent earthquakes. In Proceedings from the second international conference on recent advances in geotechnical engineering and soil dynamics (ed. S. Prakash), vol. 2, pp. 1799-1819. Rolla, MO, USA: Missouri University of Science and Technology.
Sánchez-Sesma, F. J. (1987). Site effects on strong ground motion. Soil Dynam. Earthq. Engng 6, No. 2, 124-132.

Sánchez-Sesma, F. J., Faccioli, E. \& Fregonese, R. (1986). An index for measuring the effects of topography on seismic ground motion intensity. Earthq. Engng Struct. Dyn. 14, No. 5, 719-731.

Sánchez-Sesma, F. J., Chávez-Pérez, S., Suárez, M., Bravo, M. A. \& Pérez-Rocha, L. E. (1988). The Mexico Earthquake of September 19, 1985- on the seismic response of the Valley of Mexico. Earthq. Spectra 4, No. 3, 569-589.

Seed, H. B., Romo, M. P., Sun, J. I., Jaime, A. \& Lysmer, J. (1987). Relationships between Soil Conditions and Earthquake Ground Motions in Mexico City in the Earthquake of September 19, 1985. Report No. UCB/EERC-87/15. Berkeley, CA, USA: University of California Berkeley.

Seed, H. B., Romo, M. P., Sun, J. I., Jaime, A. \& Lysmer, J. (1988). Relationships between soil conditions and earthquake ground motions. Earthq. Spectra 4, No. 2, 687-730.

Singh, S. K. \& Ordaz, M. (1993). On the origin of the long coda observed in the lake-bed strong-motion records of Mexico City. Bull. Seismol. Soc. Am. 83, No. 4, 1298-1306.

Singh, S. K., Mena, E. \& Castro, R. (1988). Some aspects of source characteristics of the September 19, 1985 Michoacán earthquake and ground motion amplification in and near Mexico City from strong motion data. Bull. Seismol. Soc. Am. 78, No. 2, $451-477$.

Tsogka, C. \& Wirgin, A. (2003). Simulation of seismic response in an idealized city. Soil Dyn. Earthq. Engng 23, No. 5, 391-402.

Whitman, R. V. (1986). Are the soil depositions in Mexico City unique? In The Mexico earthquakes-1985. Factors involved and lessons learned (eds M. A. Cassaro and E. M. Romero), pp. 163-177. New York, NY, USA: American Society of Civil Engineers.

Wirgin, A. \& Bard, P. Y. (1996). Effects of buildings on the duration and amplitude of ground motion in Mexico City. Bull. Seismol. Soc. Am. 86, No. 3, 914-920. 